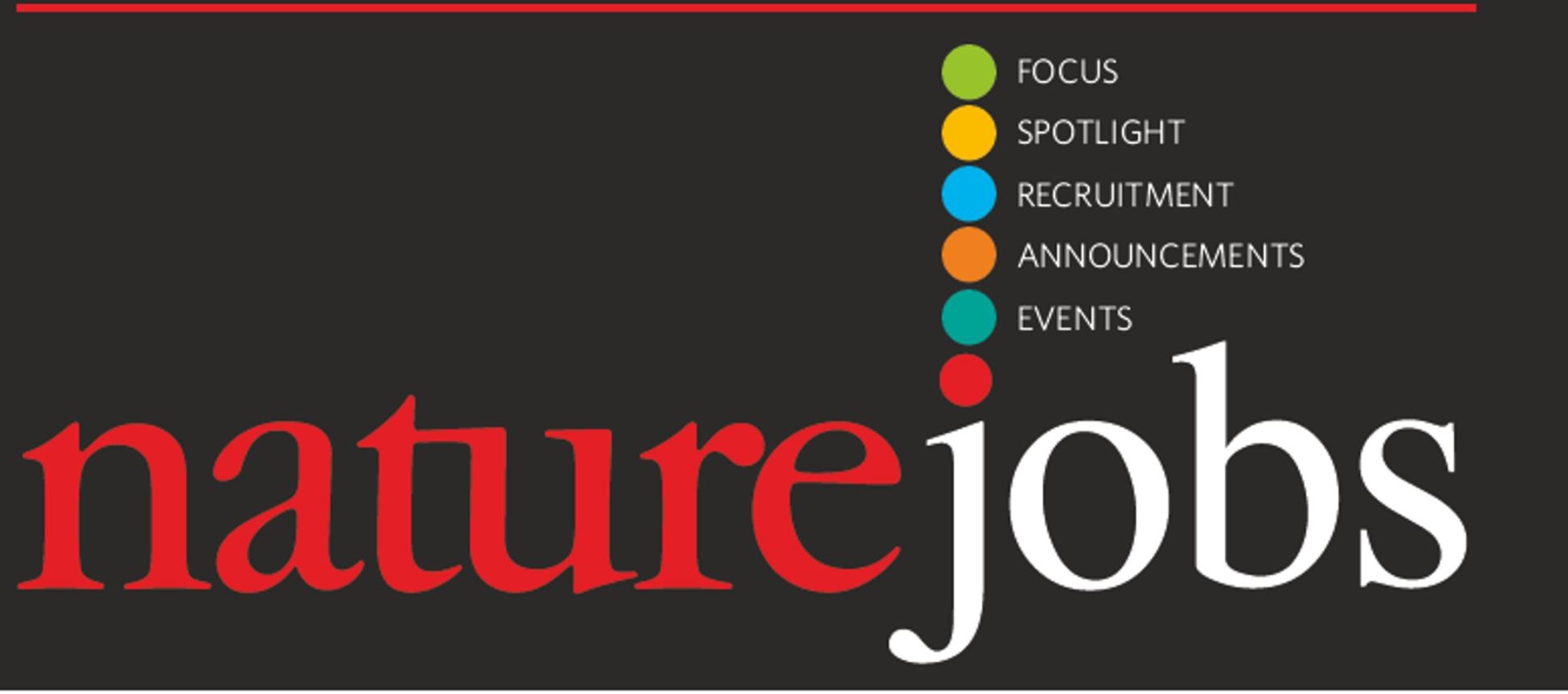

\title{
Take your partner by the hand...
}

Drug development is like a dance: it's difficult to do alone, and can be less satisfying. A report released last week shows that more biotechs are seeking partners for a bit of a bop. But pairing up with a partner entails some risks. When one half of a partnernership dances a tango and the other a waltz, someone's toes are going to get trampled.

Critical Factors for Alliance Formation, from the consultancy company Deloitte, shows that the number of alliances forged between biotech companies more than doubled between 1999 and 2003. The biggest reason, of course, is that partnerships increase the availability of cash for research and development. But two key reasons relating to personnel rank close behind. Companies often need scientific expertise that they don't have in-house and they also need an effective sales and marketing team once they have a product.

Are all these new partnerships leading to redundancies, clearing the dance floor of jobs? Not necessarily. Biotech employment in the United States and Asia has been on the rise, although the sector has been a bit flat in Europe (see Nature 435, 997; 2005). But it does mean that when seeking a suitable biotech to work for, one should study not just the potential employer, but all its partners, then see which of your skills will help out everyone.

It also means that one skill in particular - intellectual property (IP) management - will be more in demand.

There was a time when biotechs mostly licensed out their technology and drug targets to pharmaceutical companies. Now they are dancing an IP two-step: sending some intellectual property out as well as bringing some in. This means there are potentially more jobs around for intellectual property managers - but at biotechs rather than at pharmaceutical companies.

Practising until you have a well-rounded skill set, both in science and in intellectual property, will allow you to face the music and dance - whatever size your partner.

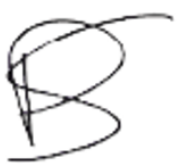

Paul Smaglik, Naturejobs editor
CONTACTS

Publisher:Ben Crowe

Editor: Paul Smagik

Marketing Manager: David Bowen

European Head Office, London

The Macmillan Building, 4 Crinan Street

London N1 9XW, UK

Tet +44(0) 207843496

$\mathrm{Fac}+44(0) 2078434996$

e-mall naturejobs@nature com

Naturejabs Sales Director:

Nevin Bayoumi (4978)

European Sales Manager:

Andy Douglas (4975)
Natireevents Sales Manager:

SileOpstup (4994)

UKVRoW/Ireland/litaly:

Nis Moeller (4953)

Irene Viglig-Alton (4944)

Scandinavia/Spain/Portugat:

Evelina Rubio Hakansson (4973)

Fance/S witzerland/Belgium:

Amele Pequignot (4974)

Germany/Austria/The Netherlands:

Reya Sliso (4970)

Advertising Production Manager:

Bite franklin

To send materials use London

address above
Tet $+44(0) 2078434814$

$\mathrm{Fax}+44(0) 2078434996$

e-mallnaturejobs@onture com

Naturejobs web de velopment Tom Hancock

Naturejo bs on line production: Niamh Shields

European Satelite OHfice

Germany/Austria/

The Netherlands:

Patrick Phelan

Tet+4989549057 11

Fax +498954905720

e-mail:p phelan@inaturecom

USHead Otfice, New York 345 Pak Avenue South. 10th Floo, New York

NY $10010-1707$

Tet +18009897718

Fac +18009897103

e-mailnaturejobs@iaturenxoom

US Sales Manager: Peter Bless

Japan Head Otfice, Tokyo

Chiyoda Bulling,

2-37 I higayatamachi.

Shinjukutku.

Tokyo 162-0843

Tet+81332678751

$\mathrm{Fac}+8133268746$

Asia-Pacific Sales Director: Rinolo Asam

e-mat tasamignaturejpncom 